\title{
Cultura política fragmentada: o papel do capital social na democratização brasileira
}

\author{
Marcello Baquero* \\ Maria Salete Souza A morim*
}

\begin{abstract}
R esumo: O dojetivo deste trabalho é o de examinar o impacto (ou não) de fatores históricoestnuturais na configuração de una cultura política fragmentada que privilegia o "eu", ao invés da coletividade no Brasil. Argumentamos que tais fatores contribuem para gerar pouca motivação para que as pessoas participem de atividades políticas, provocando uma instabilidade societária que se materializa em atitudes e comportamentos que, de maneira geral, desvalorizam a adesão a princípios democráticos, a despeito da institucionalização de procedimentos poliárquicos. Os dados examinados, oriundos de pesquisas realizadas em vários níveis de análise (macro, meso e micro), convergem para mostrar que a decepção com a política e seus representantes não é algo conjuntural, mas tem se desenvolvidb numa matriz estrutural ao longo do tempo. En tais circunstâncias, sugerimos que o conceito de capital social pode ser útil, por meio do empoderamento das pessoas, para resolver o problema da ação coletiva.
\end{abstract}

Palavr as-chave: democracia, altura política, capital social, participação política.

Introdução

U m dos avanços mais significativos na área de política comparada, nosúltimos anos, tem sido o desenvolvimento de bancos de dados empíricos que possibilitam estudos comparativos sobre os tipos de culturas políticas existentes em países com situações econômicas, políticas e culturais diferentes.

Tais dados permitem que se testem al gumas teorias em relação à forma, por exemplo, como os brasileiros decodificam a política em seus vários domínios e, sobretudo, possibilitam verificar se as atitudes internalizadas em relação à política se transformam em comportamentos e

\footnotetext{
* Professor do Programa de Pós-Graduação em Ciência Política da Universidade Federal do Rio Grande do Sul. Email: baquero@ vortex.ufrgs.br

** Professora do curso de Ciências Sociais da Unioeste, Campus de Toledo (PR).E-mail: salete.amorim@uol.com.br
}

se estes af etam (ou não) o processo de construção democrática.

Nesse sentido, o tema da cultura política, que por muito tempo deixou de ser considerado importante, ressurge na ciência política contemporânea, buscando dar conta das mudanças ocorridas em virtude da onda de democratização que transformou a maior parte dos sistemas políticos em novas democracias. No entanto, constata-se que a simples institucionalização de regras e normas democráticas, num contexto de agravamento social, não é indicativo de estabilidade política nem assegura uma mudança comportamental dos atores políticos. A legitimidade de um regime tem sido associada ao apoio, à confiança e ao grau de satisfação dos cidadãos em relação às instituições democráticas. Dados de pesquisas revelam que, no caso brasileiro, apesar do apoio à democracia, tem se agravado a crise de credibilidade e legitimidade das instituições democráticas. 
A pesquisa realizada pelo Programa das Nações U nidas para o Desenvolvimento (Pnud), ${ }^{1}$ que teve como propósito analisar os níveis de apoio político e percepção dos latino-americanos em relação à democracia, aponta que esses países, apesar de conviverem com elevados índices de pobreza e desigual dade, apresentam um índice de apoio positivo em relação à democracia (IAD $=2,03){ }^{2}$ Segundo os dados, cerca de $30 \%$ dos entrevistados não têm o hábito de participar da política; 33,2\% dos latinoamericanos intervêm esporadicamente na política, por meio do voto, e apenas $37,6 \%$ dos cidadãos intervêm na vida pública do seu país através da participação eleitoral e de outras atividades políticas. Entretanto, eleições periódicas, limpas e transparentes não são suficientes para garantir a estabilidade democrática, especialmente em sociedades em que a dimensão material não foi resolvida.

A maior parte dos estudos levados a cabo sobre cultura política mostra que se, por um lado, há uma base de apoio difuso entre os cidadãos latino-americanos, por outro, é grande a decepção causada por graves problemas sociais, contribuindo para o distanciamento, o descrédito e a desconfiança dos cidadãos em relação à política e às instituições políticas democráticas. "Instituições políticas que perdem credibilidade e a persistência das situações de pobreza e exclusão social constituem um cenário complexo que torna as democracias vulneráveis frente à ingerência dos poderes fáticos" (Relatório Pnud, 2004, p. 175). Poderes esses, representados pelas famílias tradicionais, grupos econômicos e meios de comunicação, que influenciam e intervêm diretamente nas decisões governamentais. Os meios de comunicação, geral mente pertencentes ou ligados a grupos econômicos de poder, são os principais contrapesos do poder político.

A ssim, a democracia no contexto brasilei ro apresenta dois desafios: 1) encontrar soluções políticas a seus problemas políticos e sociais,

1. Foram entrevistadas 18.643 pessoas, em 18 países da A mérica Latina, em maio de 2002.

2. $O$ IAD pondera o tamanho das orientações (democrata, ambivalente, não-democrata) com a distância e 0 nível de ativismo político das pessoas. buscando formas alternativas de participação política e de controle do poder público; 2) encontrar soluções para a desigualdade social e a pobreza, buscando al cançar uma cidadania de alta intensidade. Tais desafios suscitam uma questão operacional: como resgatar os cidadãos para a esfera da política, incentivando-os a participar e a fiscalizar as ações governamentais, de maneira a contribuir para uma melhor qualidade da democracia?

N esse contexto, o objetivo deste artigo é 0 de examinar a influência (ou não) da cultura política existente no B rasil no desenvolvimento de uma base normativa de apoio à democracia. As crenças e atitudes que têm sido internalizadas em relação à política, os níveis de confiança dos cidadãos em relação às instituições democráticas e o grau de partici pação e envol vimento político encontrados no país e demais países da A mérica Latina configuram hoje numa base normativa de apoio à democracia e numa cultura política democrática? Para a análise de tais variáveis, serão utilizados os bancos de dados disponibilizados pelo L atinobarômetro (1996) e pelo Cesop (Estudos de Comportamento Eleitoral - Eseb, 2003), al ém dos dados de pesquisa tipo survey realizadas no Rio Grande do Sul. B usca-se, com esses dados, identificar a existência (ou não) de padrões de predisposições das pessoas em vários níveis de análise (A mérica L atina, Brasil e Porto A legre) em relação à política. Dessa forma, trata-se de estudo histórico-descritivo-empírico.

Basicamente, interessa-nos examinar três questões:

1) fatores histórico-estruturais agem como obstácul os à pl ena democratização do país?;

2) o tipo de cultura política que se materializa no Brasil obedece a uma mescla de resignação com hostilidade em relação à política?;

3) o capital social ajuda a resgatar predisposições nos cidadãos para se engajar na política?

0 trabalho está estruturado em três partes. A primeira faz um retrospecto da origem, evolução e do significado do conceito de cultura política, destacando as matrizes histórico- 
estruturais que condicionam a configuração da cultura política brasileira. A segunda parte analisa dados referentes a como os latinoamericanos e brasileiros estruturam suas crenças e valores a respeito da política. A última parte examina o potencial do conceito de capital social no empoderamento dos brasileiros.

\section{O renascimento da cultura política}

A partir do momento em que o processo de democratização se inicia no Brasil, as atenções voltaram-se para analisar a forma como o desenvolvimento econômico afetaria a reconstrução institucional do país. Temia-se que a crise da dívida interna e externa, bem como os ajustes estruturais que incidiram negativamente no crescimento econômico comprometeriam o processo de construção institucional. Os mais pessimistas visualizavam regressões para o autoritarismo, pois, no passado, as crises que levaram a rupturas institucionais deram-se num contexto de crise de credibilidade e legitimidade, concomitantemente com uma situação econômica precária.

A história encarregou-se de mostrar que tais temores eram infundados, pois, apesar de uma grave crise econômica e social e uma crise da representação política, não presenciamos tentativas de volta ao passado autoritário. $\mathrm{Na}$ perspectiva da literatura da terceira onda de democracia (Huntington, 1994), chega-se a argumentar que nunca houve tantos países democráticos como na virada do milênio, passando de 22 em 1922 para 143 no ano de 2002. Nas palavras de Fukuyama (1995), a hegemonia do paradigma da democracia liberal de mercado sepultou quaisquer possibilidades de ingerência castrense na política.

No entanto, não se pode concluir que o tipo de democracia existente hoje em países como 0 $B$ rasil, que se encontram em processo de construção democrática, seja o desejado pela população, pois, do ponto de vista material (moradia, saúde, educação, transporte coletivo), a situação é preocupante. 0 índice de desemprego cresce linearmente; a insegurança da população institucionaliza-se; surgem Estados paralelos que desafiam o poder instituído; a corrupção propagase em todos os âmbitos do país, tanto público, como privado. Como conseqüência, as pesquisas de opinião revelam uma crescente indiferença das pessoas sobre o que ocorre na arena política, criando um ambiente de falta de confiança interpessoal e institucional. A questão que desafia os cientistas políticos e o governo é de como construir uma democracia sólida em condições de pobreza, desigual dade e exclusão social.

0 enfoque que tem prevalecido para explicar a permanência do regime democrático em condições adversas no B rasil fundamentase nos princípios poliárquicos, que vêem nas instituições o único caminho para a plena consolidação democrática. N essa perspectiva de análise, a democracia é vista como conseqüência da existência de procedimentos e regras. A dimensão social é encarada como algo secundário ou dependente da moldura institucional. No caso brasileiro, a maior parte da literatura institucionalista sugere que atual mente vivemos numa democracia estável, relativamente consolidada, em virtude da institucionalização de procedimentos e regras do jogo democrático. Se esse raciocínio estivesse correto, como explicar a grave crise de credibilidade e legitimidade pela qual o país atravessa? Por crise, referimo-nos à situação atual, na qual as contradições da sociedade brasil eira não conseguem ser mais resolvidas eficientemente pelas instituições mediadoras tradicionais, entreE stado e sociedade (partidos e Congresso).

Parece-nos que uma razão para a permanência de uma situação de instabilidade tem a ver com a forma como se define estabilidade. Se ela é definida estritamente em termos processual istas e formais, sem dúvida há estabilidade. Porém, esse tipo de estabilidade é amplamente favorável a determinados grupos e organizações. Por exemplo, atual mente não existem mecanismos fiscalizadores de entrada e saída de capitais do país. As grandes empresas multinacionais operam sem grandes constrangimentos institucionais. Se, por um lado, isto pode ser importante, de outro lado, se esse tipo de funcionamento não propicia as condições para o desenvolvimento interno e a melhoria das condições de vida das pessoas, pode levar a uma situação de instabilidade societária. A ssim, parece-nos que atualmente o Brasil vive esse drama: temos 
estabilidade institucional convivendo com uma instabilidade societária, que se materializa num crescente questionamento da autoridade pública, num distanciamento de qualquer tipo de envolvimento na arena política ena institucionalização do individual ismo. A spectos esses que sinalizam para a vitória do capitalismo de mercado, que não é simplesmente uma vitória econômica, mas a implementação de uma forma de ver o mundo como forma de dominação. Nessa linha de pensamento, Parraguez $(2004$, p. 1$)$ tem sugerido que "el capitalismo pertenece a una visión más amplia que es la lógica dominadora de la razón y está es la que ha establecido una fragmentación del mundo y al mismo tiempo ha generado los sistemas de vida social, económica, etc".

A convivência simultânea de uma estabilidade poliárquica com uma instabilidade societária, na nossa avaliação, tem possibilitado a manutenção de traços tradicionais e negativos da política, tais como: o clientelismo, o personalismo, o paternal ismo e o patrimonial ismo. Se o contexto mudou, as práticas mantiveram-se intactas na sua matriz operacional. O s cidadãos têm recorrido a instituições informais, para serem seus interlocutores perante o Estado, à margem das instituições convencionais referidas. Esse movimento reflete a necessidade das pessoas em construir outra perspectiva de ver o mundo, outras formas de se relacionar com a política e com as outras pessoas. Muitos autores (Foucault, 1996; B ourdieu, 1984, entre outros) têm se referido a essa busca como a institucionalização da subjetividade, do desconstrutivismo, da hermenêutica e das teorias feministas.

N ota-se que o surgimento de novas formas de ingerência política, à margem das instituições convencionais designadas para mediarem os interesses da população, particularmente os partidos, tem produzido uma situação paradoxal, na qual os partidos não sabem mais a quem representar, os políticos não sabem a quem prestar contas e o cidadão, sentindo-se desprotegido pelo Estado, recorre a outros campos de pertencimento que oscilam entre movimentos fundamentalistas religiosos e organizações altamente sofisticadas de intermediação de interesses.

$\mathrm{Na}$ área da ciência política, esses fatores têm incidido, por exemplo, no crescimento de eleitores independentes que não acreditam nas organizações vigentes. Esses indivíduos são mais pragmáticos e mobilizam-se cognitivamente (Dal ton, 2000). Em tal cenário, o fortalecimento democrático é muito difícil e o que tem se verificado, nos últimos anos, é a corrupção da democracia, na qual, segundo Sanchez Parga (2001), vive-se uma situação de regimes democráticos com Estados oligárquicos.

A creditamos ser este o caso da sociedade brasil eira contemporânea. E stamos assistindo a uma desconsolidação democrática, na qual os procedimentos poliárquicos são adaptados para serem usados dentro de uma lógica política tradicional e negativa, propiciando a manutenção da matriz de práticas que mantêm vivas modalidades de relacionamento político baseados em matrizes emocionais ingênuas. Esses fatores são al tamente danosos para a democracia.

\section{A cultura política brasileira}

U m elemento que não tem sido examinado com a devida profundidade, e que poderia auxiliar na compreensão da naturalização de uma crise de credibilidade no país, refere-se a como as pessoas internalizam, decodificam e constroem suas representações em relação à política. Em outras palavras, existem lacunas de entendimento sobre o tipo de cultura política existente no país.

$N$ ão pretendemos sugerir, defender ou polemizar sobre o que é mais importante, se instituições ou cultura política na construção democrática. Esse debate é estéril e pouco contribui para encontrar soluções à grave situação do país. Seria ingênuo imaginar que uma sociedade possa sobreviver civilizadamente sem instituições ou regras. Da mesma forma, seria inimaginável um sistema político que consiga ter uma normalidade de governo quando seus cidadãos não confiam nos seus representantes ou nas suas instituições. 0 recomendável, em tal situação, é desenvolver um enfoque compreensivo que incorpore reflexões tanto de natureza institucional, como de caráter cultural, al ém de levar em conta o impacto do cenário internacional na constituição da cultura política do país.

Presentemente, existem vários estudos culturali stas cuja contribuição para uma compre- 
ensão mais profunda dos dilemas da democratização são significativos tanto do ponto de vista teórico (A Imond e Verba, 1965; Eckstein, 1966; Pateman, 1978), quanto empíricos em relação ao Brasil (M oisés, 1995; Baquero, 2000). A proposta de um model o bal anceado na compreensão do funcionamento do regime democrático parece-nos a mais sensata. D eve-se ter presente na análise três dimensões: 1) a institucional, visando aos procedimentos democráticos; 2) a atitudinal, levando em consideração as orientações e atitudes democráticas, e 3) a comportamental, avaliada por um conjunto de hábitos políticos democráticos. A formação de uma cultura política compatível com o sistema democrático é tão importante quanto a institucional ização de um sistema partidário eficiente e de mecanismos de controle público das ações governamentais (M oisés, 1995).

0 ressurgimento da dimensão da cultura política foi propiciado pela ampla disseminação e realização de pesquisas de opinião que permitiram constatar a existência de padrões atitudinais que se vinculavam à dimensão democrática, tanto no seu sentido difuso, quanto específico (Easton, 1965). Os estudos mais importantes nessa dimensão são os de Ingl ehart (1977), que, na sua investigação sobre o pósmaterialismo, constatou uma correlação entre atitudes políticas e estabilidade democrática em 22 países. Talvez a contribuição mais importante na última década seja o estudo de Putnam (1996) sobre o impacto do capital social na construção democrática no sul da Itália. Esses estudos foram importantes no sentido de gerar um campo de reflexões sobre as perspectivas da democracia num país, em virtude do apoio ou não dos cidadãos aos princípios democráticos.

Segundo a teoria da cultura política, as normas e valores culturais, entre as quais a confiança interpessoal e a crença nas instituições democráticas, são de fundamental importância para promover a organização social, a participação política e a legitimidade do sistema político (A Imond eV erba, 1965; Putnam, 1996). Procurar entender como as pessoas pensam e percebem a política é um subsídio significativo para compreender por que um país como o Brasil não consegue sair de uma situação que se caracteriza pelo distanciamento e pela decepção por parte dos cidadãos em relação à política. Principal mente se levadas em conta as expectativas que foram criadas pelos movimentos históricos, como a M archa pelas Diretas, que pareciam sinalizar o desenvol vimento de um padrão de mobilização cidadã em caráter permanente. No entanto, o que se viu foi um crescente desapego por ela, com baixos níveis de envolvimento político, inclusive naquelas atividades convencionais. Tais elementos permitem elaborar a hipótese que o tipo de cultura política existente no país está longe de ser participativa ou crítica. Pelo contrário, ela tem sido caracterizada como híbrida (Schmidt, 2001). U ma das explicações mais significativas sobre a natureza da cultura política brasileira tem a ver com o grau de confiança que os cidadãos depositam nas instituições responsáveis pelo seu bem-estar.

\section{Crença na democracia e confiança nas instituições}

$\mathrm{Na}$ sociedade brasileira, como nas demais da A mérica Latina, não há um consenso sobre o significado de democracia. Na maioria desses países, existe uma predisposição favorável à democracia num sentido difuso, entretanto, as pesquisas de opinião mostram um crescente aumento longitudinal da desconfiança dos cidadãos em relação às instituições políticas, 0 que tem dificultado a criação de uma base normativa de apoio à democracia. Com exceção da Costa R ica, que vê a democracia em termos políticos e aponta a liberdade como o val or básico do regime democrático, os demais países da A mérica L atina encaram a democracia mais na perspectiva social e econômica e atribuem grande importância à igual dade socioeconômica. (Camp, 2001). Tais dados demonstram a pouca importância que as pessoas dão à forma democrática e a ênfase que conferem à questão material. Essa situação parece-nos ser lógica em países como o B rasil, onde a base material, como foi dito, está longe de ser resolvida.

Os dados do L atinobarômetro mostram que há uma matriz de adesão às instituições políticas e aos procedimentos democráticos, mas não necessariamente uma adesão aos valores democráticos. Em 1995, quando indagados sobre qual 
a melhor forma de governo, $56 \%$ dos brasileiros responderam que a democracia é preferível a qual quer outra forma de governo; $23 \%$ disseram que tanto faz, e $21 \%$ afirmaram acreditar que, em certas ocasiões, é mel hor o governo autoritário. 0 fato de mais de $50 \%$ preferirem a democracia não é indicativo de legitimidade do sistema político e muito menos de credibilidade. $\mathrm{N}$ a pesquisa levada a cabo em 2000, pela mesma empresa de pesquisa, o número de pessoas que responderam que, em determinadas circunstâncias, era melhor um sistema autoritário desde que este resolvesse os problemas econômicos ultrapassou os 50\%, gerando uma preocupação tanto nos meios acadêmicos, como governamentais (Relatório do Pnud, 2004). Por outro lado, quando se compara longitudinal mente o grau de satisfação dos brasilei ros com o funcionamento da democracia, constata-se que essa satisfação declinou significativamente de 1996 para 2000, sinalizando que o processo de consolidação está longe de ocorrer.

Tabela I

Satisfação com o funcionamento da democracia, por país (\%)

\begin{tabular}{ccc}
\hline & $\begin{array}{c}\text { Muito satisfeito/ } \\
\text { satisfeito } \\
1996\end{array}$ & $\begin{array}{c}\text { Muito satisfeito/ } \\
\text { satisfeito } \\
2000\end{array}$ \\
\hline Argentina & 35 & 46 \\
Brasil & 26 & 19 \\
Costa Rica & 54 & 61 \\
Chile & 28 & 35 \\
México & 1 & 236 \\
\hline $\mathrm{N}=$ 5305 &
\end{tabular}

Como podemos ver na Tabela I, os porcentuais apontam para uma grande insatisfação dos latino-americanos com o funcionamento da democracia. Essa insatisfação reflete, em parte, a insatisfação geral dos cidadãos provocada pela crise econômica e social vivenciada pelos países da A mérica L atina. Estudos apontam que 0 desenvolvimento econômico tende a fazer os cidadãos mais confiantes e desejosos por instituições democráticas e que as atitudes, crenças e valores têm um papel fundamental no comportamento e progresso humanos (Inglehart, 2002).

Nesse contexto, a confiança interpessoal e institucional, juntamente com a participação política (convencional e não-convencional), são de fundamental importância para a legitimidade e a credibilidade do sistema político.

Tabela II

Grau de confiança dos brasileiros nas instituições (Muita/ Alguma) \%

\begin{tabular}{lcc}
\hline \multicolumn{2}{c}{ (Muita/ Alguma) $\%$} & 2000 \\
\hline \multicolumn{1}{c}{ Confiança no Congresso } & 1896 & 28 \\
Confiança nos Partidos Políticos & 16 & 20 \\
$\quad$ Confiança no Governo & 23 & 39 \\
\hline $\mathrm{N}=1101$ & & \\
Fonte: Latinobarômetro 1996; Lagos,2000. & &
\end{tabular}

Os dados da Tabela II revelam que a confiança nas instituições políticas mantém-se, entre os anos de 1996 e 2000, muito abaixo de $50 \%$, tanto no Brasil, como nos demais países da A mérica L atina, índice preocupante do ponto de vista da cultura política democrática. O utro dado do L atinobarômetro confirma a indiferença dos brasileiros em relação ao Congresso e aos partidos: $42 \%$ afirmaram que pode haver democracia sem Congresso e $43 \%$ disseram que a democracia pode funcionar sem partidos políticos. D e certa forma, a desconfiança revela uma atitude crítica dos cidadãos quanto ao papel e ao desempenho das instituições políticas (Pharr e Putnam, 2000).

A descrença nos partidos políticos e no Congresso faz parte de um processo que envolve um conjunto de variáveis macroestruturais como o personalismo, o clientelismo, a corrupção, o individual ismo, que atuam no sentido de desvalorizar as instituições e fomentar a apatia e a desconfiança dos ci dadãos em rel ação à política e aos políticos. A confiança é um componente básico do capital social. Quanto maior a confiança, maior a probabilidade de cooperação e participação política (B aquero, 2000).

Tabela III

Nível de confiança na maioria das pessoas (\%)

\begin{tabular}{cc}
\hline Não confia / confia pouco & 86 \\
\hline Confia / confia muito & 14 \\
\hline Fonte: ESEB 2003
\end{tabular}

As pesquisas empíricas sugerem que a confiança, o envolvimento político e a democracia estão intrinsecamente relacionados (Putnam, 
1996; Inglehart, 2002). U m dos aspectos da cultura política que faz parte desse círculo virtuoso é a confiança interpessoal, mas a porcentagem de pessoas que não confiam nos outros é preocupante, como vimos na Tabela III. A desconfiança generalizada nas instituições políticas e a baixa confiança interpessoal comprometem ações de cooperação e de solidariedade social.

0 ceticismo em relação à política não é exclusivo dos países latino-americanos, como mostram pesquisas coordenadas pelo World Values Survey (WV S), um levantamento mundial de valores que inclui 65 países. Entretanto, 0 descrédito nas instituições políticas nos países "pós-materialistas" incide de maneira diferente no sistema político. Estudos apontam que, nas democracias industriais, as pessoas estão se tornando mais céticas e descontentes com os partidos políticos. M as, por outro lado, é crescente 0 interesse do público pela questão ambiental e pel a qualidade de vida, e observamse efetivas mudanças nos padrões de participação nos novos movimentos sociais e de apoio a eles. Do ponto de vista de Dalton (2000), os níveis de participação política em atividades consideradas não-convencionais estão se expandindo na maioria das sociedades industriais avançadas, enquanto a participação nos partidos políticos está declinando.

A questão da participação política nas democracias emergentes é bastante diferente. Como trazer os cidadãos para a esfera da política, num contexto de desconfiança generalizada nas instituições e de graves desigualdades socioeconômicas? A s pesquisas mostram que, quanto mais baixos o nível socioeconômico e 0 nível educacional da população, menor a probabilidade de se encontrar altos índices de participação política. N esse quadro de apatia e desconfiança, qual o grau de predisposição das pessoas em participar ou intervir na política?

$\mathrm{N}$ a pesquisa do Cesop/Eseb, realizada logo após o segundo turno das el eições presidenciais de 2002, os dados apontam para um baixo grau de envolvimento dos brasileiros com a campanha política e para um distanciamento dos entrevistados em relação a atividades dessa natureza.
Tabela IV

O Sr(a) participou de alguma destas atividades? (Não) \% Tentou convencer alguém a votar no seu candidato 63 Distribuiu panfletos do seu candidato $\quad 82$ Colocou cartazes na sua casa ou carro do seu candidato $\quad 75$ Participou de abaixo assinado $\quad 48$ Participou em manifestações ou protestos $\quad 82$ Participou em greves $\mathrm{N}=2513$ Fonte: ESEB, 2003

Como se pode depreender dos dados da Tabela IV, constata-se que os brasileiros, de maneira geral, não mostram predisposição para partici par de atividades políticas convencionais e não convencionais. Tal resultado é corroborado por pesquisas levadas a cabo em outras épocas (B aquero, 2000) em nível nacional. Dessa forma, pode-se argumentar que, ao longo do tempo, as instituições não têm conseguido motivar as pessoas a se engajar ativamente em campanhas el eitorais. U ma das razões para a falta de estímulo de se envolver na política pode estar no grau de confiança que os brasileiros depositam nas suas instituições. N esse caso, temos dados longitudinais que nos permitem acompanhar, ao longo do tempo, oscilações de atitudes em rel ação àquel as organizações que constituem os pilares da democracia formal.

Nas décadas de 1960 e 1970, al guns cientistas políticos argumentaram que os movimentos sociais e a excessiva participação política gerariam instabilidade ao regime democrático. Nesse sentido, seria benéfico para a democracia se as pessoas se mantivessem indiferentes e apáticas diante do processo político. ${ }^{3}$ O s estudos sobre a participação política enfatizavam a participação eleitoral ou convencional: votar em eleições, pertencer a partidos, convencer outros sobre suas idéias políticas, ao passo que a participação política não-convencional muitas vezes foi considerada como não-democrática, pois incluía atividades reivindicatórias como protestos, passeatas e greves.

A respeito dessa temática, Baquero e Prá (1995), ao analisarem os padrões de participação política no R io Grande do Sul, constataram uma

3. 0 argumento da "sobrecarga democrática" foi defendido por Crozier, Huntington e Watanuki por ocasião da publicação do Relatório da Comissão Trilateral, 1975. 
parca tradição de participação entre os gaúchos e um processo de afastamento da política por parte dos cidadãos, em virtude da desilusão com as políticas públicas e com a situação de crise vivenciada pelo país. Nessa perspectiva, a ausência de participação política no Brasil associa-se a quatro fatores: 1) apatia ou falta de interesse pela política; 2) cinismo ou suspeita em relação à política; 3) alienação ou indiferença em relação à política; 4) anomia ou perda de valores e de vontade de participar.

A s matrizes ideológicas autoritárias mantêm-se no país e os padrões tradicionais reproduzem-se. É necessário pensar em formas al ternativas de participação política, que possibilitem a construção de uma cultura política democrática. Trata-se de construir capital social, que atua no sentido de facilitar a cooperação entre os cidadãos, a confiança e o envolvimento cívico (Putnam, 1996).

\section{Capital social e empoderamento dos cidadãos}

No contexto acima descrito, a persistência da pobreza e da exclusão social proporciona um campo de reflexões alternativas sobre que outros mecanismos poderiam ser úteis na resolução desses problemas. No campo das ciências sociais, várias propostas emergiram, sinalizando caminhos à margem dos paradigmas estabelecidos. Um conceito que se fortaleceu nessa direção é o de capital social. Esse conceito permite uma análise sobre as relações entre atores dentro e entre diferentes contextos envolvidos no desenvolvimento da comunidade. Embora alguns autores (Portes, 1998) tenham sugerido que o capital social funciona muito mais num contexto localizado, são crescentes os esforços na direção de aplicá-lo numa escala macrossistêmica.

Tais esforços devem-se ao fato de se reconhecer que vivemos numa época de crise social e econômica que, ao contrário do que se pensava, está contribuindo para a erosão não só das bases de convivência pessoal e comunitária, mas das próprias bases da governabilidade, se esta é pensada em termos sociais.

Verifica-se um consenso generalizado, nas várias instâncias decisórias, tanto formais, quanto informais, sobre o significado e implicações do capital social. Há um pressuposto de que uma das conseqüências positivas desse termo é a geração de relações horizontais de apoio recíproco na dimensão social entre membros da comunidade, da família, da cidade com o Estado.

$\mathrm{Na}$ medida em que o conceito de capital social foi introduzido num contexto multidisciplinar, e pelo fato de ter entrado no círculo acadêmico como categoria analítica há menos de duas décadas, persistem problemas teóricos, de conceituação e de mensuração. No entanto, a maioria dos estudos independentes da área em que trabal ham converge para a idéia de que o capital social envolve redes de contatos, ação coletiva, estrutura social e confiança.

No contexto deste trabalho, delimitamos nosso campo de análise à dimensão cognitiva de capital social, ou seja, aos valores, crenças, atitudes, normas sociais e comportamento das pessoas em relação à dimensão política, particularmente no que diz respeito à confiança nas instituições e à confiança interpessoal. Partimos do pressuposto de que a dimensão cognitiva catalisa a predisposição dos cidadãos para se envolver em ações coletivas que gerem benefícios mútuos para a comunidade.

Nessa perspectiva, são as relações de solidariedade e os recursos por el as produzidos que constituem um tipo de fábrica social das comunidades e transformam-se em fatores essenciais para o desenvolvimento de estratégias que atuem em beneficio da comunidade.

0 capital social tem como princípio que as comunidades funcionam bem ou mal dependendo das dimensões sociais existentes. Em outras palavras, a ação coletiva somente tem êxito quando existem afinidades entre as pessoas, se elas confiam umas nas outras e se respeitam mutuamente, capacitando-as a compartilhar recursos, tanto como inputs e outputs. A ssim, auferir a existência ou não de capital social pode ajudar a detectar a fragilidade ou pontos fortes de uma comunidade. Se esse princípio é ampliado para uma cidade ou um país, é possível avaliar o grau de capital social existente.

Tradicionalmente, 0 enfoque sociocultural que domina a sociedade brasileira institucio- 
nalizou um modelo de dependência política interna no qual convivem o sujeito dominador e o sujeito dominado. A relação, portanto, é de submissão, inviabilizando o desenvolvimento da ação participativa. É muito mais uma relação impositiva. 0 que o conceito de capital social objetiva é desconstruir esse model o e substituílo por mecanismos de valorização da participação dos cidadãos, baseados na confiança recíproca e no princípio de alteridade positiva. O u seja, todos decidem, sem incorrer em assembleísmos, pois as pessoas têm consciência (estão empoderadas) da importância de chegar a conclusões (consensos) práticas e pragmáticas.

Dessa forma, evita-se o estabelecimento de uma cultura de individual ismo, do "eu", na qual o resultado será a institucionalização deuma cultura da desconfiança. N esse tipo de cultura, o objetivo de quem domina o saber é o de estimular a reprodução desse saber para controláIo, corrigi-lo e puni-lo (F oucault, 1996). A teoria do capital social visa superar esse tipo de cultura, promovendo a igual dade de oportunidades entre os cidadãos, por meio do seu empoderamento.

U ma forma de avaliar a existência de uma cul tura política orientada para o individualismo é auferindo as orientações das pessoas na escolha de um candidato durante um pleito eleitoral. Se as instituições estão, de fato, solidamente enraizadas no imaginário dos cidadãos, a expectativa seria de el es votarem guiados por critérios institucionais, nesse caso, nos partidos políticos. Se, ao contrário, prevalecem predisposições individualistas, a tendência será de uma orientação personal ista. Os dados que utilizamos para avaliar essa dimensão, num sentido longitudinal, provêm de pesquisas em nível regional, realizadas em Porto A legre. O s resultados dessa indagação são apresentados no Gráfico I.

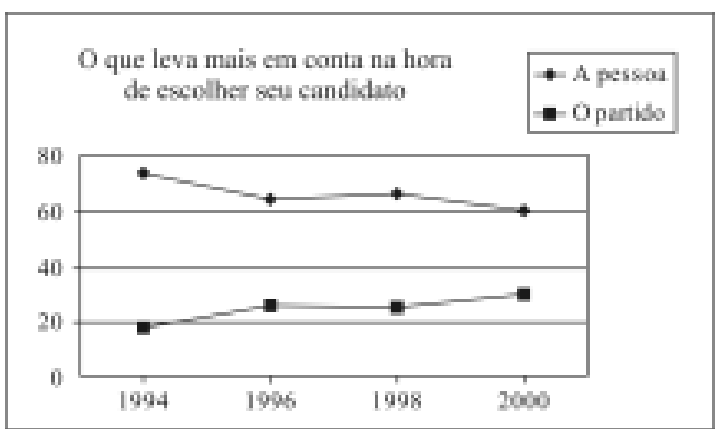

Fonte: Núcleo de Pesquisas Sobre A mérica Latina (NUPESAL). ( $N=500 \mathrm{c} / a n o)$.
Embora a tendência pareça ser de valorização da instituição, a porcentagem daqueles que se guiam por critérios personalistas passa de $60 \%$. As oscilações podem ser atribuídas a fatores de natureza conjuntural, ao passo que 0 padrão longitudinal, de caráter estrutural, mostra que a pessoa do candidato tem maior peso no momento da escolha eleitoral. Esse tipo de comportamento contribui para fortalecer a cul tura de dependência política, na qual o el eitor não passa de um mero espectador da política. Esse contexto propicia o enraizamento da fragmentação da sociedade, pois não existe um programa ou plataforma política capaz de motivar as pessoas a agir coletivamente. 0 individual ismo nessa situação é inevitável. N ão é surpresa, portanto, verificar que, em tais circunstâncias, o grau de envolvimento em atividades convencionais da política seja mínimo, conforme o Gráfico II mostra.

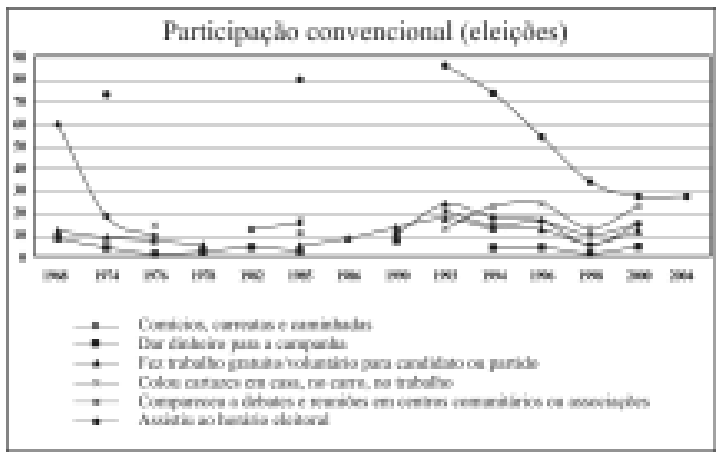

Fonte: Núcleo de Pesquisas Sobre A mérica Latina (NU PESAL). ( $\mathrm{N}=500 \mathrm{c} / \mathrm{ano}$ ).

Numa sociedade fragmentada e sem pontos de referência para a construção de identidades coletivas sólidas, a participação política tende a ser mínima. Os dados do G ráfico II são contundentes no que diz respeito ao pouco envolvimento dos cidadãos em atividades convencionais (social mente aceitas e formal mente institucionalizadas). 0 padrão observado é de uma estabilidade negativa nessas atividades. As oscilações estão dentro da margem de erro e, portanto, não demonstram alterações significativas. É o que se pode chamar de um crescimento inercial, pois, a despeito dos avanços institucionais, a motivação das pessoas para se engajar em atividades políticas émínima. A única atividade que mostra um movimento diferenciado é a que se refere à audiência do horário el eitoral 
gratuito, o qual, previsivel mente, inicia com índices elevados, fruto da reentrada do país na democracia representativa. Porém, esse índice começa a declinar na medida em que o processo poliárquico se institucionaliza, mostrando que, quando as expectativas geradas pelo processo de redemocratização não são cumpridas, o interesse por se envolver na política, por parte dos cidadãos, experimenta um processo denominado por al guns autores de fadiga el eitoral. A fadiga e a indiferença das pessoas em relação ao que acontece no país podem ser al tamente deletérias para o processo de consolidação democrática.

Os dados sugerem que a cultura do "eu" institucionalizou-se, contribuindo para a exclusão do conceito genuíno de participação. 0 envolvimento é ritualizado e não representa um processo de empoderamento das pessoas. A ssim, a participação instal ada na estrutura geral de uma cultura de dependência não pode prosperar (Parraguez, 2004).

U m caminho al ternativo para estimular as pessoas a participar da dimensão de capital social diz respeito ao envolvimento dos cidadãos em organizações informais, que, de certo modo, podem substituir as tarefas de educação política que não são cumpridas pelas organizações convencionais responsáveis. De fato, não se pode negar que tem havido uma proliferação de organizações cujo objetivo é potencializar canais alternativos de intermediação política. Nos chamados países desenvolvidos, esse tipo de atividade está institucionalizado, porém, em países como o Brasil, ainda estamos longe de ter os mesmos índices de envolvimento nas referidas associações. Tal fato fica cristalizado no Gráfico III.

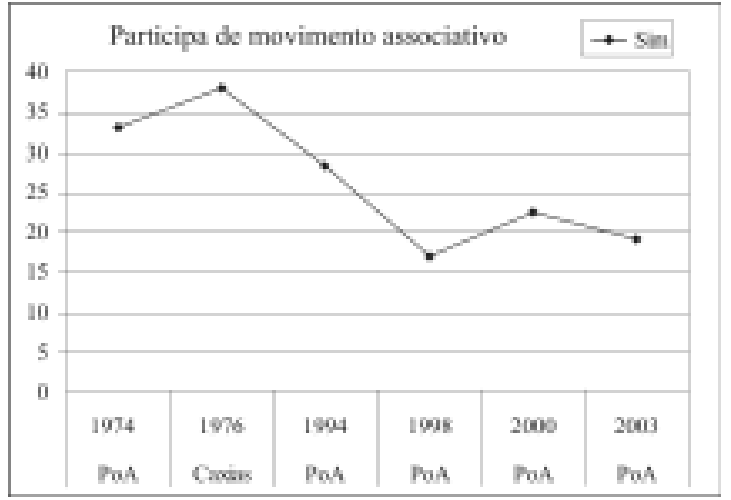

Fonte: Núcleo de Pesquisas Sobre A mérica Latina (N upesal). (N = 500 c/ano).
0 padrão de envolvimento em associações informais, de acordo com os dados do Gráfico III, está em declínio. Se tomados como parâmetro de comparação os dados de 1994 para Porto A legre, observa-se que a redução é significativa (de 28\% para 17\%); as oscilações para 0 ano 2000 e 2003 estão dentro da margem de erro. Esses dados sugerem a ausência de capital social. Portanto, não é só o Estado que tem fracassado na constituição de capital social, mas, a despeito da proliferação de organizações informais, estas não conseguem estimular uma maior participação dos cidadãos, contribuindo para baixos estoques de capital social. Nesse cenário, assistimos à estruturação de uma cultura de massas que não produz cidadãos e que separa o Estado da sociedade. É como se o Estado fosse dos governantes e a sociedade civil, dos cidadãos. Se, porcentualmente, uma minoria envolve-se em qualquer das duas esferas, 0 resultado não pode ser outro, senão uma cultura política fragmentada, na qual o Estado assume paternal isticamente a responsabilidade pelo bemestar coletivo da nação, gerando uma situação híbrida, na qual o governante toma as decisões sem vivenciar ou entender em profundidade a crise social e, por outro lado, o cidadão vivencia a situação de exclusão social, mas não élevado em conta quando são decididas as políticas públicas.

\section{Consider ações finais}

A vinculação entre procedimentos poliárquicos e estabilidade democrática tem se convertido em lugar-comum nosúltimos anos em países como o B rasil, que estão em processo de solidificação de sua democracia. Não se pode negar que avanços significativos têm sido alcançados. Do ponto de vista institucional, é inegável que presentemente o país vive uma situação diferente de épocas passadas. No entanto, como é típico de sociedades que não conseguem resolver eficientemente seus problemas de ordem material (saúde, moradia, educação e desemprego), em curto prazo entram numa área cinzenta, onde, de maneira geral, instala-se um certo pessimismo sobre o futuro do país. 0 paradoxo é que essa incerteza ocorre no momento em que o Estado de Direito parece se solidificar. 
Não há, por exemplo, temores fundados sobre a possibilidade de uma regressão institucional ou a volta de um Estado de exceção, apesar da crise econômica e social que assola o país. Então por que os cidadãos, segundo os dados de pesquisa de opinião levadas a cabo nos últimos anos, insistem em mostrar uma postura atitudinal de repúdio em relação às instituições políticas e seus representantes?

Os dados aqui examinados apontam que a questão social é fundamental para o futuro da democracia no país. Basicamente, a situação resume-se a como solidificar um sistema democrático em condições de expansão da pobreza, crescente desigualdade social e aumento da exclusão social.

Isso significa que, para promover uma cultura política de participação, a dimensão da confiança institucional e interpessoal deve ser majoritária. A articulação entre Estado e sociedade deve ser bem mais dinamizada. A s bases sobre as quais isto pode ocorrer é por meio do desenvolvimento de novos significados de cidadania, configurados em torno de identidades locais, comunitárias e sociais. A questão é: como alcançar esse objetivo? Parece-nos que um dos caminhos que se apresenta com potencial emancipatório da cidadania no atual contexto é a promoção de capital social, definido em termos da promoção da confiança recíproca e solidariedade social. Fazer críticas à utilidade desse conceito, o que geralmente tem ocorrido, é ignorar que ele ainda não tem sido testado ou identificado suficientemente no B rasil.

Os dados que foram examinados apontam para a existência de um estoque reduzido de capital social. É necessário, portanto, primeiro promover o capital social e observar seus efeitos, antes de simplesmente decretar sua falência. No entanto, para promovê-lo, é imperativo enfrentar obstáculos que impedem sua materialização, entre os quais podemos citar os vícios tradicionais da política (paternalismo, clientelismo e patrimonialismo) (questão I). Em segundo lugar, é necessário reconhecer que o tipo de cultura política existente no país tem privilegiado o individual ismo, o particularismo e o distanciamento da política. Superar essa situação envolve grandes esforços por parte da sociedade e do Estado em investir maciçamente na educação emancipatória e libertadora. Se essa meta não for atingida, o máximo que se pode esperar é uma democracia instável convivendo com uma cultura societária hostil à política (questão II). Finalmente, está claro que formas al ternativas de participação política, por meio de organizações informais, vieram para ficar. É um fenômeno que ainda não foi analisado academicamente em profundidade, mas que, na realidade, funciona como mecanismo alternativo de intermediação de interesses para os cidadãos que se sentem excluídos pel as políticas públicas. Cabe ressal tar que o número de pessoas que se utilizam desse mecanismo ainda é reduzido, mas em franco crescimento. U ma forma de lidar com esses movimentos de maneira eficiente é desenvolvendo uma sinergia (modelo compreensivo) entre os atores sociais envolvidos na promoção do bem-estar da comunidade, com vistas a promover o capital social (questão III).

\begin{abstract}
A bstract: This article has as its main dojective to analyze the impact (or not) of historical-structural factors in the configuration of a fragmented political culture that privileges the "me" instead of the collectivity in Brazil. Such factors, we argue, do not contribute to stimulate the citizens to participate in political activities, generating societary instability that materializes in attitudes and behaviors that in a general way do not value the attadment to democratic principles, even in a situation in which the poliarquical procedures are institutionalized. The data analyzed from several levels of analysis (macro, meso and micro) converge to show that deception with the political institutions and politicians is not something temporary, but it has developed into a stnuctural matrix. In such circumstances, we suggest that the concept of social capital could be useful, though empowerment of the citizens, in order to solve the problem of collective action.
\end{abstract}

K ey-words: democracy, political alture, social capital, political participation.

\section{Referências}

ALM OND, G. eVERBA, S. The civic culture. Political attitudes and democracy in five nations. Boston: Little B rown and Co., 1965.

BA QUERO, M arcelo; PRÁ, J ussara. M atriz históricoestrutural da cultura política no Rio Grande do Sul e padrões de participação política. Cadernos de Ciência Política. P PG-CP, UFGRS, 1995. 
- A vulnerabilidade dos partidos políticos e a crise da democracia na América Latina. Porto A legre: Ed. U niversitária/U FRGS, 2000.

BOURDIEU, Pierre. Q uestions de sociologie. Paris: M inuit, 1984.

CA M P, Roderic Ai. Citzen views of democracy in Latin America. Pittsburgh: University of Pittsburgh, Press, 2001.

CROZIER, M.J; HUNTINGTON, S.P.; WATA NUKI, $J$. The crisis of democracy. Report on the governability of democracies to the Trilateral Commission. N ew Y ork: N ew York U niversity Press, 1975.

DA LTON, Russell J . Citizen attitudes and political behavior. Comparative Political Studies, vol. 33, n. 6/7, Sage Publications, Inc, A ugust/September, 2000.

EA STON, David. A framework for political analysis. Englewood Cliffs, N.J. Prentice-Hall, 1965.

ECK STEIN, Harry. Division and cohesion in democracy. A study of norway. Princeton: Princeton University Press, 1966.

FOU CA ULT, M ichel. Vigiar e punir: o nascimento da prisão. Petrópolis: Vozes, 1996.

FUK UYA M A, Francis. Trust. The social virtues and the creation of prosperity. N ew York: The F ree Press, 1995.

HUNTINGTON, Samuel. A terceira onda: a democratização no final de século. São Paulo: Á tica, 1994.

INGLEHART, Ronald. The silent revolution: Changing values and political styles. Princeton: Princeton U niversity Press, 1977.

. Cultura e democracia. In: HARRISON, L. e HUNTINGTON, S. (Orgs). A cultura importa. Rio de J aneiro: Record, 2002.
LA GOS, M arta. B etween stability and crisis in L atin A mérica. J ournal of D emocracy, v. 1, n. 1, J anuary, 2001

MOISÉS, José Álvaro. Os brasileiros e a democracia. Bases sociopolíticas da legitimidade democrática. São Paulo: Ática, 1995.

PA RRA GUEZ, M anuel J. M odelo de participación por afección: un modelo para el desarrollo de la ciudadania local. In: www.bcs.org. A cesso em: 26/7/ 2004.

PATEM A N, Carole. Participação e teoria democrática. Rio de J aneiro: Paz eTerra, 1978.

PHARR, Susan; PUTNAM, Robert. Disaffected democracies. What's troubling the trilateral countries? Princeton: Princeton U niversity Press, 2000.

PORTES, A lejandro. Social capital: Its origins and applications in modern sociology. Annual Review of Sociology, v. 24, 1998, p.1-24.

PUTNA M , Robert D. Comunidade e democracia: a experiência da I tália moderna. Rio de Janeiro: FGV, 1996.

RELATÓRIO DO PROGRAMA DAS NAÇÕES UNIDAS PARA O DESEN VOLVIMENTO - PNUD. $L$ a democracia en $A$ merica $L$ atina: para una democracia de ciudadanas y ciudadanos. Buenos A ires: A guilar, A Itea, Taurus, A lfaguara, S. A ., 2004.

SA NCHÉZ-PARGA，J. Transformaciones del conflicto, decline de los movimientos sociales y teoria del desgobierno. Ecuador D ebate, Quito, $\mathrm{n}$. 53, p. 19-40, ago. 2001.

SCHIMDT, João Pedro. Juventude e política no Brasil: a socialização política dos jovens na virada do milênio. Santa Cruz do Sul: Edunisc, 2001. 